\title{
The Effect of Addition of ppm-Order-Pd to Fe-K Catalyst on Dehydrogenation of Ethylbenzene
}

\author{
Ryo Watanabe, Yasushi Sekine, Masahiko Matsukata and Eiichi Kikuchi \\ Department of Applied Chemistry, Waseda University \\ Japan
}

\section{Introduction}

Styrene, used for polymeric materials such as polystyrene resin, acrylonitrile-butadienestyrene resin, and styrene-butadiene rubber, is an important monomer in the petrochemistry (Meima et al., 2001). The styrene production volume is about 23 million tons annually; more than $90 \%$ of styrene is produced by dehydrogenation of ethylbenzene, as in the following chemical equation (1) (Shekhah et al., 2004).

$$
\mathrm{C}_{8} \mathrm{H}_{10} \rightarrow \mathrm{C}_{8} \mathrm{H}_{8}+\mathrm{H}_{2}
$$

Dehydrogenation of ethylbenzene is an endothermic reaction. High temperatures are necessary for high ethylbenzene conversion because of its thermodynamic limitation. Potassium promoted iron oxide (Fe-K) has been applied for dehydrogenation of ethylbenzene as an industrial catalyst (Lee, 1974). The Fe-K catalyst can be further modified by the addition of other promoters such oxides as $\mathrm{MgO}, \mathrm{Cr}_{2} \mathrm{O}_{3}, \mathrm{CeO}_{2}$ and $\mathrm{MoO}_{3}$ (Eggertsen et al., 1947; Kearby et al., 1945; O'Hara, 1975; Pitzer, 1957; Riesser, 1979).

Generally, radial-type adiabatic reactors have been applied in commercial processes for dehydrogenation of ethylbenzene (Addiego, 2001). Superheated steam is supplied to the catalyst bed with ethylbenzene as a heating source for control of the reaction temperature. Steam also acts as a diluent for shifting the equilibrium conversion higher and suppresses over-reduction of the catalyst in the dehydrogenation atmosphere. Additionally, steam has the role of elimination of carbon deposition on the catalyst surface. The removal of coke from the catalyst surface using steam treatment improved the catalytic activity and that a low $\mathrm{H}_{2} \mathrm{O}$ /ethylbenzene ratio caused coke deposition on the catalyst (Herzog et al., 1984; Devoldere et al., 1999). It was also reported that the increasing the feed molar-ratio of $\mathrm{H}_{2} \mathrm{O}$ /ethylbenzene decreased the carbon deposition (Coulter et al., 1995).

The reaction mechanism of dehydrogenation of ethylbenzene on the Fe-K catalyst has been investigated widely. Langmuir-Hinshelwood (L-H) type including chemisorption of ethylbenzene and styrene proceeded on the Fe-K catalyst according to kinetic studies (Carrà et al., 1965). Analysis of infrared spectroscopy indicated that ethylbenzene adsorbed with the phenyl ring oriented to a- $\mathrm{Fe}_{2} \mathrm{O}_{3}$ (Busca et al., 1984). The styrene adsorption state on a$\mathrm{Fe}_{2} \mathrm{O}_{3}$ catalyst was reported that styrene adsorbed via the vinyl group on the catalyst. (Addiego et al., 1994). The result of isotope exchange reaction revealed that the dissociation 
of a-hydrogen of ethylbenzene was the first step of ethylbenzene dehydrogenation, followed by the dissociation of $\beta$-hydrogen, which was the rate-determining step or post rate-determining step. (Miura et al., 1994)

Some researchers investigated the active phase of the Fe-K catalyst and showed $\mathrm{KFeO}_{2}$ phase as the active site for dehydrogenation of ethylbenzene using a combination of XPS/UPS surface analysis (Hirano et al., 1986; Muhler et al., 1989, 1992). The active state of the Fe-K catalyst was analysed by transient response experiments and reported that initially high activity was correlated with $\mathrm{Fe}^{3+}$ state and the reduction from $\mathrm{Fe}^{3+}$ to $\mathrm{Fe}^{2+}$ state caused deactivation of the catalytic activity (Zhu et al., 2004). The reaction cycle was proposed that ethylbenzene adsorbed onto a terrace $\mathrm{Fe}^{3+}$ site; then $\mathrm{C}-\mathrm{H}$ in the ethyl group was deprotonated by lattice oxygen at a step site. $\mathrm{H}_{2} \mathrm{O}$ containing a lattice oxygen was postulated to desorb on the catalyst instead of $\mathrm{H}_{2}$, meaning that oxidative dehydrogenation proceeded on the Fe-K catalyst (Weiss et al., 2000).

Recently, it was reported that the addition of small amounts of Pd or Pt enhanced the activity of Fe-K based catalysts (Williams et al., 2002). Previously we investigated hydrogen production by the steam-iron reaction using iron oxide modified with very small amounts of $\mathrm{Pd}$ at the temperature of $723 \mathrm{~K}$ and under atmospheric pressure. The addition of ppmorder $\mathrm{Pd}$ to iron oxide enhanced rates of the reduction by $\mathrm{H}_{2}$ and the oxidation by $\mathrm{H}_{2} \mathrm{O}$ (Urasaki et al., 2005). This work is intended to clarify the role of added precious metals such as $\mathrm{Pd}$ and $\mathrm{Pt}$ in relation to the reaction mechanism of dehydrogenation of ethylbenzene on the Fe-K catalyst (Sekine et al., 2008).

\section{The activity for dehydrogenation of ethylbenzene over ppm-order $\mathrm{Pd} / \mathrm{Fe}-\mathrm{K}$ catalyst}

For investigating the effect of $\mathrm{Pd}$ addition to the Fe-K catalyst on dehydrogenation activity and selectivity to styrene, we compared the result of activity tests on the Fe-K catalyst and Pd-promoted Fe-K catalyst. (Section 2.1) And also, the effect of Pd loading on dehydrogenation activity was investigated in the section 2.2.

\subsection{Comparison of the activity and selectivity over Pd/Fe-K catalyst to those over bare Fe-K catalyst}

Catalysts used in this study were commercially available Fe-K catalyst and Pd/Fe-K catalyst prepared by an impregnation method on the Fe-K catalyst. Fe-K mixed oxide which contained some promoters such as $10 \mathrm{wt} \% \mathrm{~K}_{2} \mathrm{O}, 10 \mathrm{wt} \% \mathrm{CeO}_{2}$ and trace amounts of $\mathrm{MoO}_{3}, \mathrm{MgO}$ and $\mathrm{CaO}$ immersed in an aqueous solution of the metal precursor salt of $\mathrm{Pd}\left(\mathrm{NO}_{3}\right)_{2}$. The amount of $\mathrm{Pd}$ was 10, 30, 300 and $1000 \mathrm{ppm}$. Then, the resulting slurry was dried on a hot plate under continuous stirring with subsequent calcination at $873 \mathrm{~K}$ for $6 \mathrm{~h}$. Pt catalyst was prepared using the same impregnation method with an acetone solution of $\mathrm{Pt}\left(\mathrm{CH}_{3} \mathrm{COO}\right)_{2}$.

The reactor used in this study comprised of a quartz tube (12-mm i.d.) containing the catalyst bed, which was fixed by quartz wool. A type K thermocouple enclosed in a quartz thermowell of 3-mm outer diameter was positioned inside the catalyst bed for accurate measurement of the catalyst temperature.

Catalytic activities, selectivities and stabilities were examined in a conventional fixed bed flow reactor. The weight of charged catalyst was $1.0 \mathrm{~g}$. Reactions were carried out at $813 \mathrm{~K}$ at 
atmospheric pressure in the presence of steam; the molar ratio of steam to ethylbenzene was 12 and WHSV was $1.2 \mathrm{~g} \mathrm{~h}^{-1} \mathrm{~g}_{\text {-cat }}^{-1}$. Ethylbenzene and $\mathrm{H}_{2} \mathrm{O}$ were fed separately using a micro feeder and a micro pump, respectively. Liquid products such as ethylbenzene, benzene, toluene and styrene were analysed using off-line flame ionization detection (FID) gas chromatography (GC8A; Shimadzu Corp.) with a capillary column of DB210 (0.25 mm×30 m) using $\mathrm{N}_{2}$ as a carrier gas at $373 \mathrm{~K}$. Tetralin was used as an internal standard substance. Gaseous products such as $\mathrm{H}_{2}, \mathrm{CO}$ and $\mathrm{CH}_{4}$ were analyzed using an off-line thermal conductivity (TCD) gas chromatography (GC8A; Shimadzu Corp.) with a $3 \mathrm{~mm} \times 2 \mathrm{~m}$ stainless steel column packed with active carbon (60/80 mesh) using Ar as a carrier gas at $393 \mathrm{~K}$.

$$
\begin{gathered}
\text { Ethylbenzene conversion }=([\text { Sty }]+[\mathrm{Bz}]+[\mathrm{Tol}]) /([\mathrm{EB}]+[\text { Sty }]+[\mathrm{Bz}]+[\mathrm{Tol}]) \times 100 \\
\text { Styrene yield }=[\text { Sty }] /([\mathrm{EB}]+[\text { Sty }]+[\mathrm{Bz}]+[\mathrm{Tol}]) \times 100 \\
\text { Styrene selectivity }=[\text { Sty }] /([\text { Sty }]+[\mathrm{Bz}]+[\text { Tol }]) \times 100
\end{gathered}
$$

In these equations, [EB], [Sty], [Bz], and [Tol], respectively represent the yield of ethylbenzene, styrene, benzene, and toluene. Carbon balances of these investigations amounted to $\geq 95 \%$.

For investigating the effect of $\mathrm{Pd}$ addition to the Fe-K based catalyst on dehydrogenation activity and selectivity, activity tests of the $\mathrm{Fe}-\mathrm{K}$ and $10 \mathrm{ppm}-\mathrm{Pd} / \mathrm{Fe}-\mathrm{K}$ catalysts were carried out.

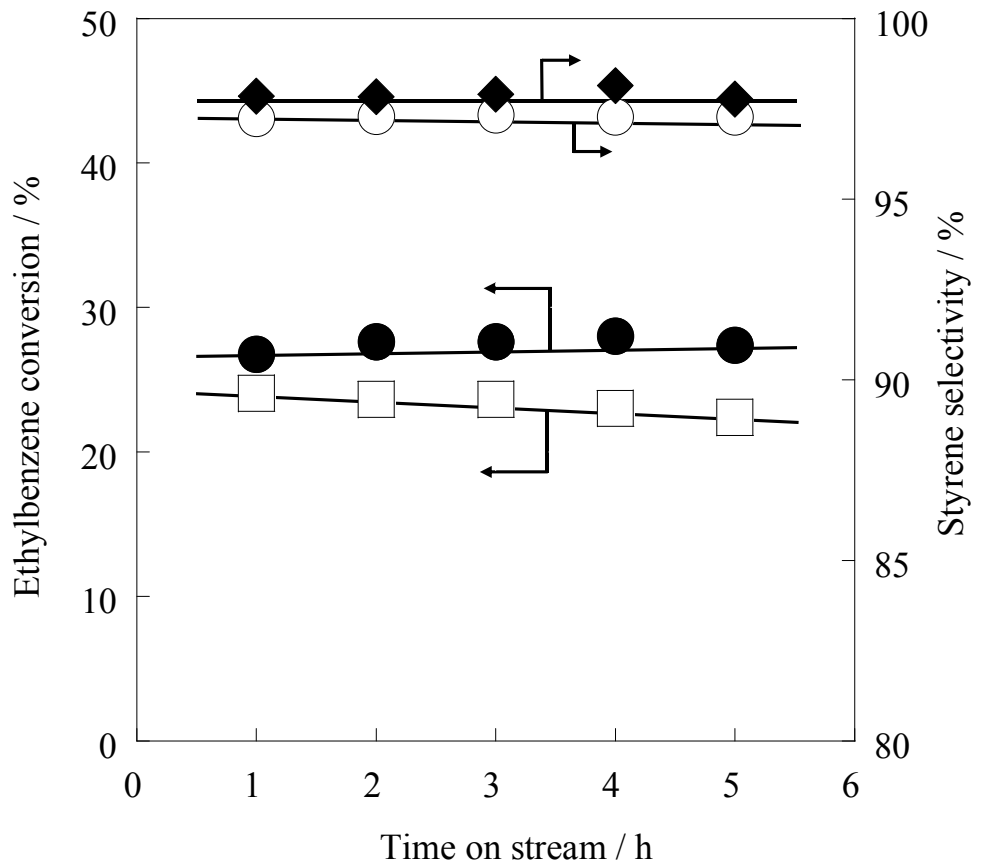

Fig. 1. Ethylbenzene conversion and styrene selectivity of $(\square, \bigcirc) \mathrm{Fe}-\mathrm{K}$ catalyst and $\mathrm{Pd} / \mathrm{Fe}-\mathrm{K}$ catalyst. 
Figure 1 shows the conversion of ethylbenzene and selectivity to styrene for these catalysts with time on stream. The Fe-K catalyst showed $24.1 \%$ of conversion at $1 \mathrm{~h}$ reaction. Ethylbenzene conversion was gradually decreased to $22.4 \%$ at $5 \mathrm{~h}$ reaction. On the other hand, 10 ppm-Pd/Fe-K catalyst showed $26.8 \%$ of conversion at $1 \mathrm{~h}$ reaction and $27.4 \%$ of conversion at $5 \mathrm{~h}$ reaction. The addition of small amount of Pd enhanced the activity for dehydrogenation of ethylbenzene over the Fe-K catalyst. Catalytic activity of $10 \mathrm{ppm}-$ $\mathrm{Pd} / \mathrm{Fe}-\mathrm{K}$ catalyst was stable for 3 to $5 \mathrm{~h}$ at least. As for the selectivity to styrene, the Fe-K catalyst showed 97.2 and $97.3 \%$ at $1 \mathrm{~h}$ and $5 \mathrm{~h}$, respectively. Benzene and toluene were formed as by-products with selectivities of $1.1 \%$ and $1.7 \%$, respectively. While, $10 \mathrm{ppm}$ $\mathrm{Pd} / \mathrm{Fe}-\mathrm{K}$ catalyst revealed $97.8 \%$ selectivity to styrene at $1 \mathrm{~h}$ and $5 \mathrm{~h}$. Selectivities to benzene and toluene were $1.1 \%$ and $1.1 \%$, respectively at $1 \mathrm{~h}$. The effect of addition of ppm-order-Pd to the Fe-K catalyst enhanced for dehydrogenation activity drastically and also improved selectivity to styrene.

\subsection{The promotion effect of $\mathrm{Pd}$ on dehydrogenation activity of Fe-K catalyst}

From section 2.1, we found that the trace amount of Pd addition to the Fe-K catalyst enhanced dehydrogenation activity. So, the promotion effect of Pd loading (the amount of $\mathrm{Pd} ; 10,30,300$ and $1000 \mathrm{ppm}$ ) on the Fe-K catalyst on dehydrogenation activity was investigated. Figure 2 shows the result of activity tests over various catalysts.

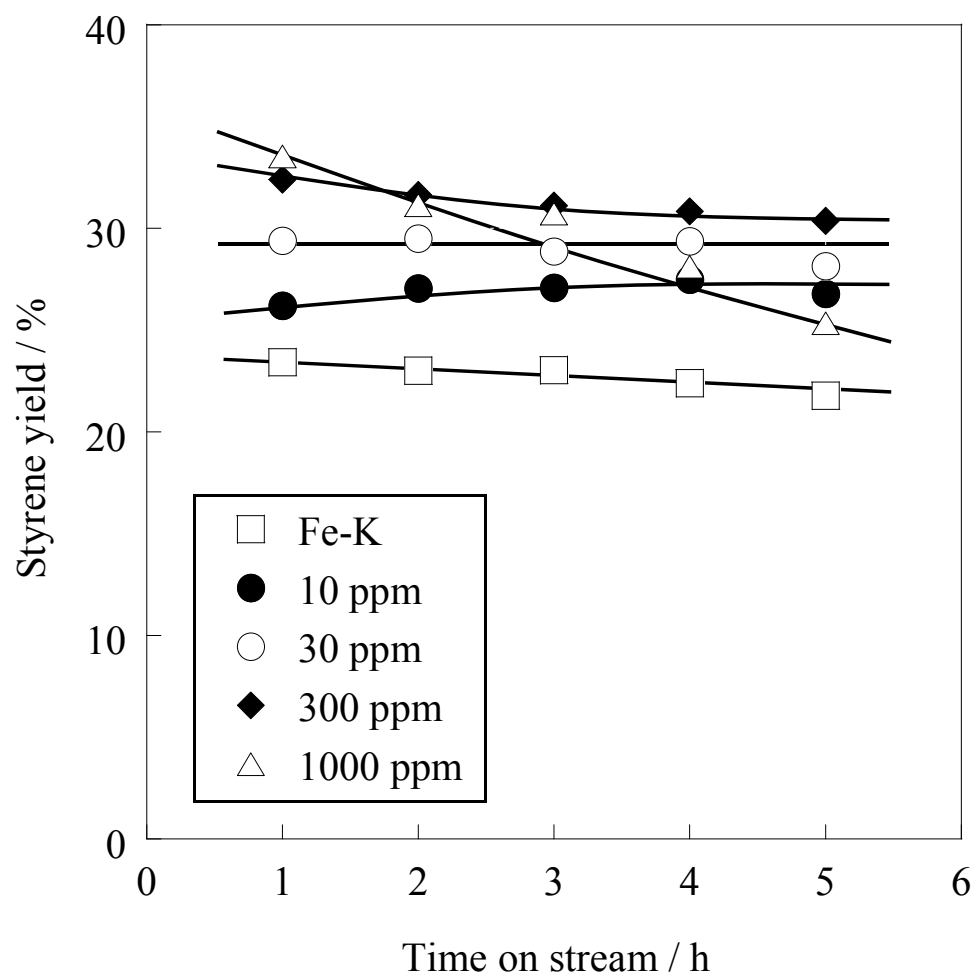

Fig. 2. The effect of Pd loading on styrene yield. 
Figure 2 reveals that the conversion of ethylbenzene increases from $23.4 \%$ to $33.5 \%$ at $1 \mathrm{~h}$ reaction with increasing the amount of Pd. Figure 3 shows the relation between the initial catalytic activity and Pd concentration. As shown in fig. 2, catalysts of $10 \mathrm{ppm}-\mathrm{Pd} / \mathrm{Fe}-\mathrm{K}$ and $30 \mathrm{ppm}-\mathrm{Pd} / \mathrm{Fe}-\mathrm{K}$ showed high stability for dehydrogenation of ethylbenzene with time on stream. However, deactivation proceeded on catalysts of $300 \mathrm{ppm}-\mathrm{Pd} / \mathrm{Fe}-\mathrm{K}$ and 1000 ppm-Pd/Fe-K. From fig. 3, the effect of the addition of Pd seems to be saturated at a few hundred ppm of Pd on the surface of catalyst. Therefore, the optimum amount of Pd was less than $300 \mathrm{ppm}$ in terms of activity and stability for dehydrogenation of ethylbenzene.

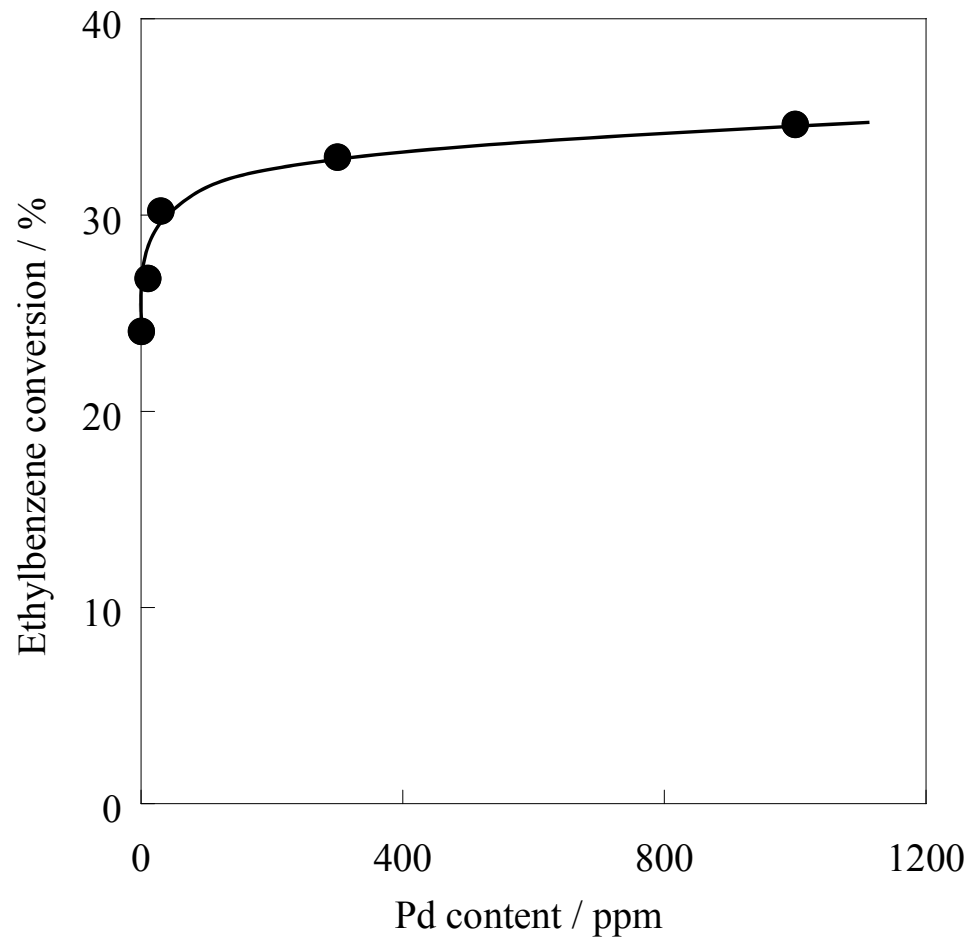

Fig. 3. Relation between the initial catalytic activity and Pd concentration.

For investigating the effect of the $\mathrm{Pt}$ addition to the $\mathrm{Fe}-\mathrm{K}$ catalyst on dehydrogenation activity and selectivity, the activity test of $\mathrm{Pt} / \mathrm{Fe}-\mathrm{K}$ catalyst was carried out in the fixed-bed flow reactor at $813 \mathrm{~K}$. Loading of Pt on the Fe-K catalyst was equivalent mole of $300 \mathrm{ppm}-$ $\mathrm{Pd} / \mathrm{Fe}-\mathrm{K}$ catalyst. Figure 4 shows the result of activity and selectivity of the $\mathrm{Fe}-\mathrm{K}, \mathrm{Pd} / \mathrm{Fe}-\mathrm{K}$ and Pt/Fe-K catalysts. As shown in fig. 4, Pt/Fe-K catalyst showed $36.5 \%$ and $31.6 \%$ of conversion at $1 \mathrm{~h}$ and $5 \mathrm{~h}$, respectively. Comparing conversion of $\mathrm{Pt} / \mathrm{Fe}-\mathrm{K}$ catalyst and $\mathrm{Fe}-\mathrm{K}$ catalyst, trace amounts of $\mathrm{Pt}$ also enhanced the activity of the Fe-K catalyst. However catalytic activity of $\mathrm{Pt} / \mathrm{Fe}-\mathrm{K}$ catalyst gradually decreased with time on stream. Styrene selectivity was almost the same to that of the Fe-K catalyst. The result indicated the active site did not change by the addition of trace amounts of $\mathrm{Pt}$ to the Fe-K catalyst. 


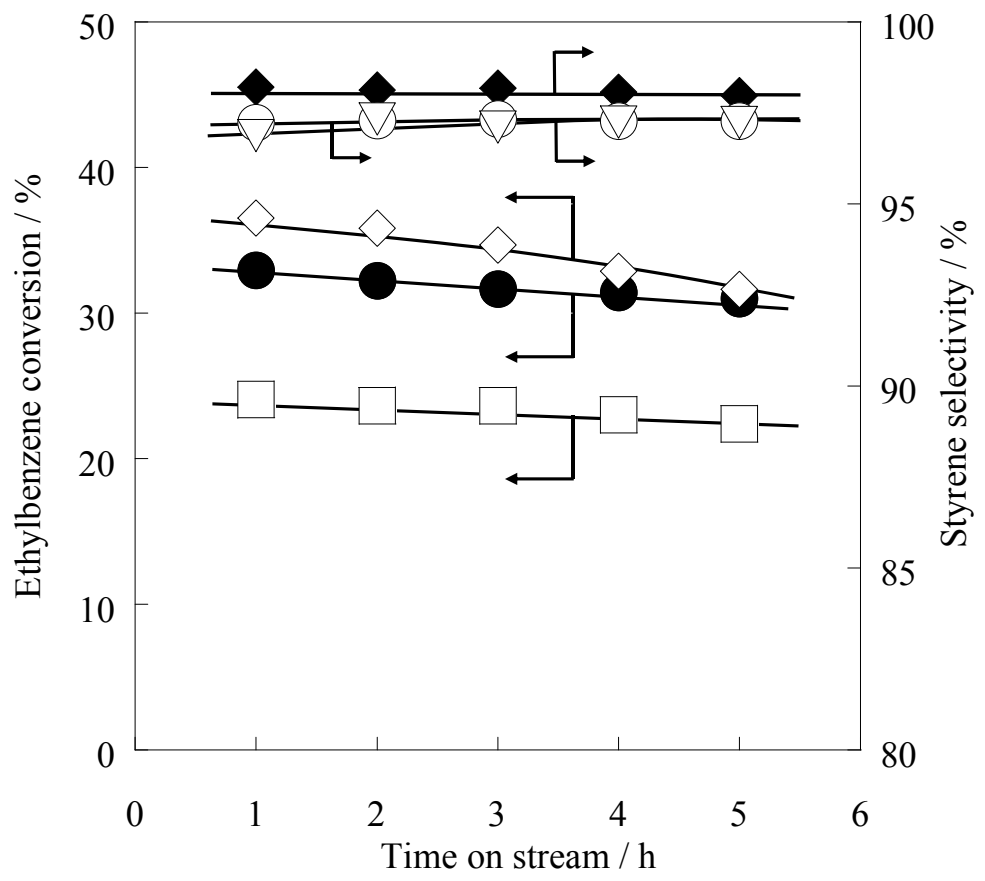

Fig. 4. Ethylbenzene conversion and styrene selectivity of $(\square, \bigcirc)$ Fe-K catalyst, $(\bullet, \bullet) \mathrm{Pd} / \mathrm{Fe}-$ $\mathrm{K}$ catalyst and $(\diamond, \nabla) \mathrm{Pt} / \mathrm{Fe}-\mathrm{K}$ catalyst.

\section{Reaction mechanism of dehydrogenation of ethylbenzene over Pd/Fe-K catalyst}

In order to clarify the role of $\mathrm{Pd}$, we investigated the reaction mechanism using periodical pulse experiments with reactants of ethylbenzene and $\mathrm{H}_{2} \mathrm{O}$ supplied alternately to the catalyst bed. The period of each pulse was $600 \mathrm{~s}$. The weight of charged catalyst was $1.0 \mathrm{~g}$. Ethylbenzene and $\mathrm{H}_{2} \mathrm{O}$ were supplied using a bubbler with $\mathrm{He}$ as a carrier gas. The molar ratio of ethylbenzene to He was $1 / 20$; the total flow rate was $7.8 \times 10^{-2} \mathrm{~mol} \mathrm{~h}^{-1}$. The molar ratio of $\mathrm{H}_{2} \mathrm{O}$ to $\mathrm{He}$ was $1 / 8$, and the total flow rate was $8.4 \times 10^{-2} \mathrm{~mol} \mathrm{~h}^{-1}$. Reaction temperature was $783 \mathrm{~K}$. The product composition at the reactor outlet was monitored continuously using an on-line quadruple mass spectrometer (HPR20; Hiden Analytical Ltd.). Calibration of mass spectrometer signals was based on prepared mixtures of a known composition. For all periodical experiments, the gas-phase composition was calculated from the mass signal at the following m/e $=2\left(\mathrm{H}_{2}\right), 4(\mathrm{He}), 18\left(\mathrm{H}_{2} \mathrm{O}\right), 78$ (styrene), and 91 (ethylbenzene).

Figure 5 shows the fraction of $\mathrm{H}_{2} \mathrm{O}$ in produced hydrogen species $\left(\left[\mathrm{H}_{2} \mathrm{O}\right] /\left(\left[\mathrm{H}_{2}\right]+\left[\mathrm{H}_{2} \mathrm{O}\right]\right)\right.$ and the conversion of ethylbenzene when the pulse test was conducted on the $\mathrm{Fe}-\mathrm{K}$ catalyst. 


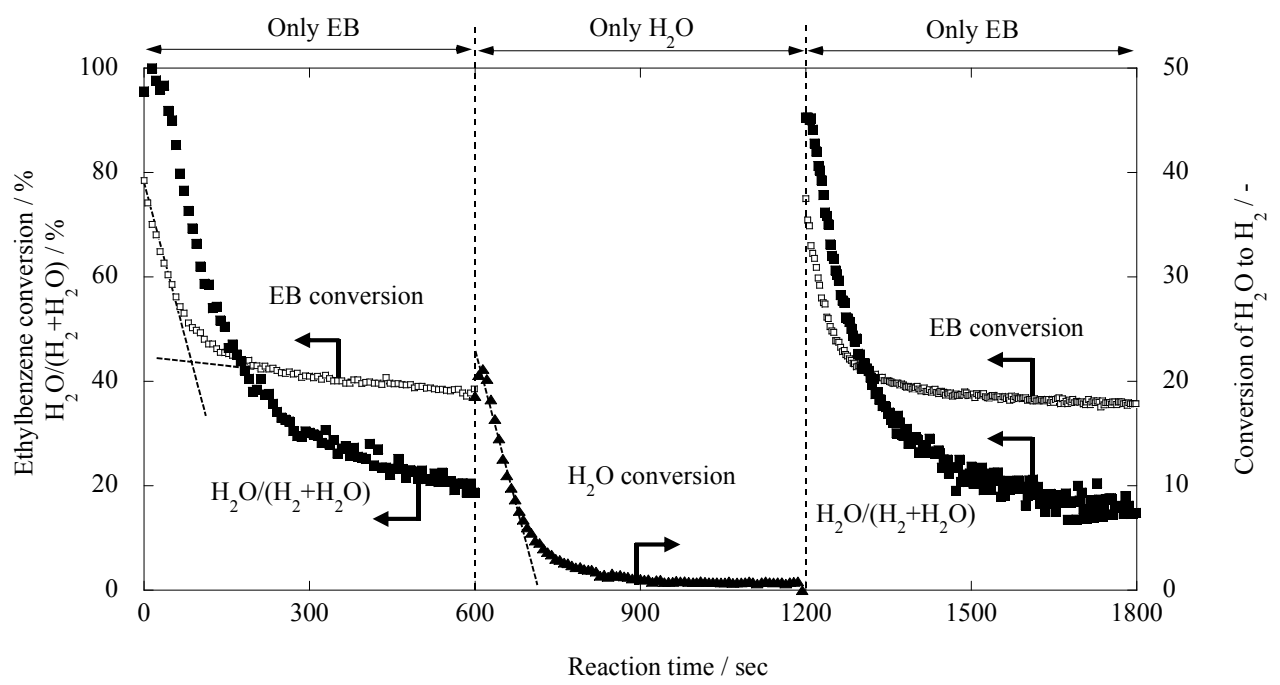

Fig. 5. Results for the periodical pulse reaction test over the Fe-K catalyst (Sekine et al., 2008).

In the case of feeding EB-alone to the catalyst bed, products were styrene and $\mathrm{H}_{2} \mathrm{O}$ at the initial stage of the reaction. $\mathrm{H}_{2}$ was gradually produced with decreasing of $\mathrm{H}_{2} \mathrm{O}$ production. The fraction of $\mathrm{H}_{2} \mathrm{O}$ and the conversion of ethylbenzene showed a high value at the starting time of the reaction. This steep and straight decrease of ethylbenzene conversion from $0 \mathrm{~s}$ to $100 \mathrm{~s}$ could be attributed to the domination of oxidative dehydrogenation of ethylbenzene (5) because the ratio of $\mathrm{H}_{2} \mathrm{O} /\left(\mathrm{H}_{2}+\mathrm{H}_{2} \mathrm{O}\right)$ was close to 1 at the early stage of the reaction.

$$
\mathrm{C}_{8} \mathrm{H}_{10}+\mathrm{O}^{2-} \text { lat } \rightarrow \mathrm{C}_{8} \mathrm{H}_{8}+\mathrm{H}_{2} \mathrm{O}+\mathrm{V}_{\text {ox }}+2 \mathrm{e}^{-}
$$

Here, $\mathrm{O}^{2-}$ lat denotes lattice oxygen in the Fe-K catalyst and $\mathrm{V}_{\text {ox }}$ shows the lattice vacancy. Oxidative dehydrogenation, by which styrene and $\mathrm{H}_{2} \mathrm{O}$ were formed, competed with and progressed faster than, the simple dehydrogenation (6) (Langmuir-Hinshelwood type reaction) which formed styrene and $\mathrm{H}_{2}$.

$$
\mathrm{C}_{8} \mathrm{H}_{10} \rightarrow \mathrm{C}_{8} \mathrm{H}_{8}+\mathrm{H}_{2}
$$

Afterward, the conversion of ethylbenzene and fraction of $\mathrm{H}_{2} \mathrm{O}$ decreased and reached a steady state. When $\mathrm{H}_{2} \mathrm{O}$ supplied to the catalyst bed after feeding EB-alone, we confirmed the production of $\mathrm{H}_{2} \cdot \mathrm{H}_{2}$ was considered to be produced through the following reaction (7).

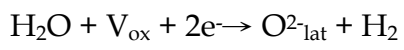

Then, EB-alone was supplied to the catalyst bed again. We observed the formation of styrene and $\mathrm{H}_{2} \mathrm{O}$ as products. The reactivity seemed to be recovered by the oxidation of the catalyst by $\mathrm{H}_{2} \mathrm{O}$. Hence, we concluded that the steady-state reaction mechanism of dehydrogenation of ethylbenzene on the catalyst was redox-type using the lattice oxygen in the catalyst. 
We also investigated the reaction mechanism of $30 \mathrm{ppm}-\mathrm{Pd} / \mathrm{Fe}-\mathrm{K}$ catalyst using periodical pulse experiments with reactants of ethylbenzene and $\mathrm{H}_{2} \mathrm{O}$ supplied alternately to the catalyst bed. Figure 6 shows the results of the modified Fe-K catalyst with small amount of Pd.

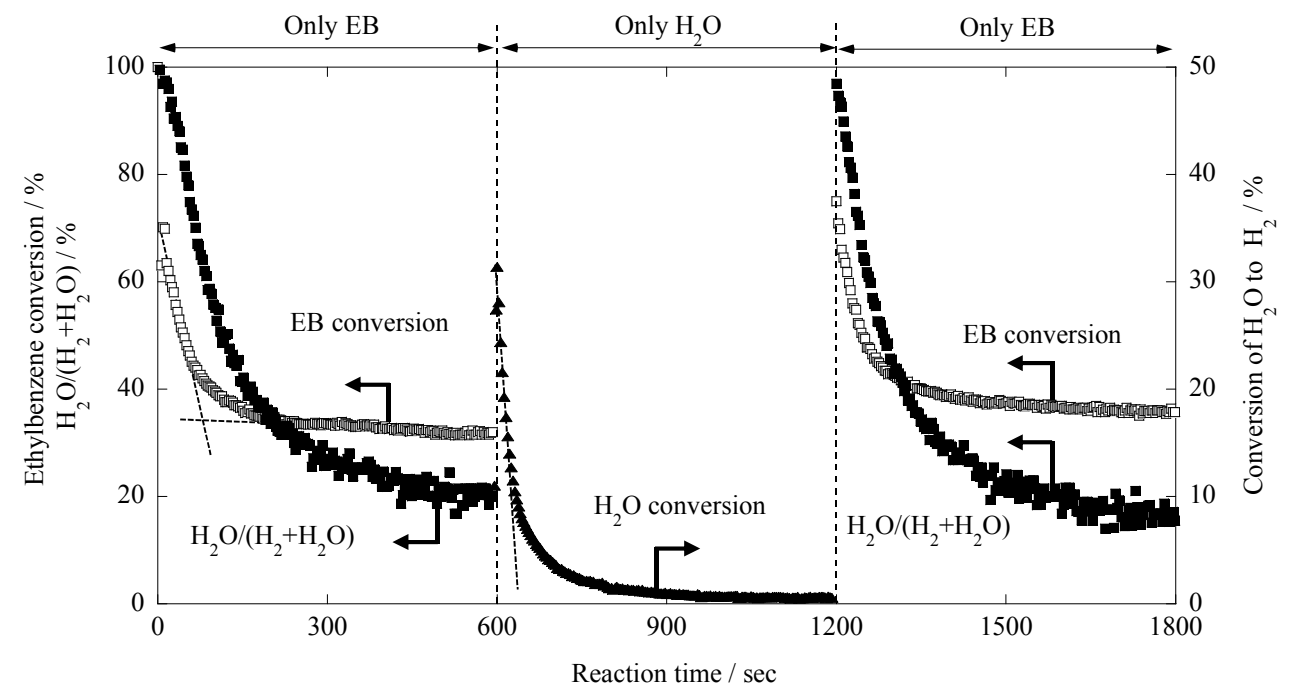

Fig. 6. Results for the periodical pulse reaction test over the $30 \mathrm{ppm}-\mathrm{Pd} / \mathrm{Fe}-\mathrm{K}$ catalyst.

Oxidative dehydrogenation of ethylbenzene (5) also proceeded on the catalyst by using lattice oxygen in the catalyst. And simple dehydrogenation (6) proceeded on the catalyst when lattice oxygen in the catalyst was consumed. After feeding EB-alone, $\mathrm{H}_{2} \mathrm{O}$ supplied to the catalyst bed. $\mathrm{H}_{2}$ was also produced by the oxidation of the catalyst by $\mathrm{H}_{2} \mathrm{O}$ (7). When EBalone was supplied to the catalyst again, the reactivity was recovered by the oxidation of the catalyst by $\mathrm{H}_{2} \mathrm{O}$. Therefore we concluded that redox-type mechanism using the lattice oxygen proceeded on the catalyst. Comparing results of periodical experiments of the Fe-K catalyst and $\mathrm{Pd} / \mathrm{Fe}-\mathrm{K}$ catalyst, there was a difference in the formation rate of $\mathrm{H}_{2} . \mathrm{Pd} / \mathrm{Fe}-\mathrm{K}$ catalyst revealed higher oxidation rate at $600 \mathrm{~s}$. So, the effect of ppm-order-Pd addition to the Fe-K catalyst on the enhancement dehydrogenation activity was investigated in terms of reaction mechanism in the next section.

\section{The role of $\mathrm{Pd}$ on dehydrogenation of ethylbenzene in terms of reaction mechanism}

For investigating the role of $\mathrm{Pd}$ for dehydrogenation of ethylbenzene in terms of reaction mechanism, we calculated the ratio of amounts of reactive lattice oxygen to total amounts of lattice oxygen in the catalyst and elucidated the effect of ppm-order Pd addition on redox property of catalysts (Section 4.1). And also, we considered the relation between the redox property of the catalyst and activity for dehydrogenation of ethylbenzene in this section 4.2. 


\subsection{Promotion of regenerating rate of lattice oxygen}

We compared rates of release/regenerating of lattice oxygen over the Fe-K catalyst and $\mathrm{Pd} / \mathrm{Fe}-\mathrm{K}$ catalyst from figures 5 and 6 . Here, the release rate of lattice oxygen was regarded as styrene formation rate at the time when feeding of ethylbenzene was started and regenerating rate of lattice oxygen was regarded as $\mathrm{H}_{2}$ formation rate at the time when feeding of $\mathrm{H}_{2} \mathrm{O}$ was started after feeding of EB-alone. Figure 7 shows the $\mathrm{O}^{2}{ }^{-}$lat balance in the catalysts during periodic pulse experiments.

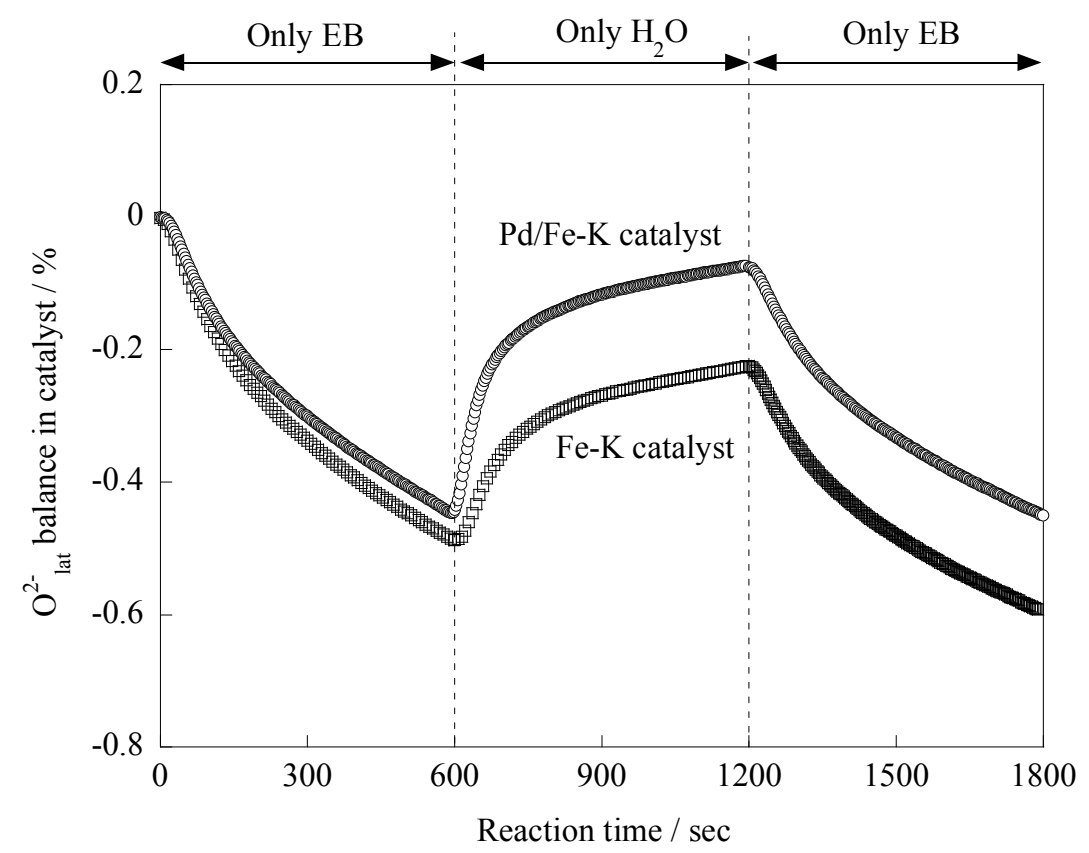

Fig. 7. Lattice oxygen balance in Fe-K and $30 \mathrm{ppm}-\mathrm{Pd} / \mathrm{Fe}-\mathrm{K}$ catalyst in the periodic pulse experiments (Sekine et al., 2008).

From figures 5, 6 and 7, we found the steep and straight decrease of ethylbenzene conversion from $0 \mathrm{~s}$ to $100 \mathrm{~s}$ could be attributed to the domination of oxidative dehydrogenation of ethylbenzene. So the amount of lattice oxygen was calculated by integration of releasing lattice oxygen from $0 \mathrm{~s}$ to $100 \mathrm{~s}$. As a result, the amount of lattice oxygen showing high reactivity was inferred to be $1.7 \times 10^{-5} \mathrm{~mol} \mathrm{~g}^{-1}$, which was about $25 \%$ of surface lattice oxygen from the BET surface area (ca. $2 \mathrm{~m}^{2} \mathrm{~g}-1$ ). The amount of lattice oxygen decreased in a straight trend in 100$600 \mathrm{~s}$, implying that the concentration of surface lattice oxygen reached a steady state and dominated by the bulk diffusion. On the other hand, we found that the lattice oxygen that was consumed by ethylbenzene was regenerated by $\mathrm{H}_{2} \mathrm{O}$ because $\mathrm{H}_{2}$ was formed by the reaction with $\mathrm{H}_{2} \mathrm{O}$. The initial conversion of $\mathrm{H}_{2} \mathrm{O}$ to $\mathrm{H}_{2}$ was $20 \%$ at $600 \mathrm{~s}$ in fig. 5, subsequently, the conversion of $\mathrm{H}_{2} \mathrm{O}$ decreased. The regeneration rate of lattice oxygen decreased from $1.7 \times 10^{-7} \mathrm{~mol} \mathrm{~s}^{-1} \mathrm{~g}^{-1}$ to $4.1 \times 10^{-8} \mathrm{~mol} \mathrm{~s}^{-1} \mathrm{~g}^{-1}$ at $700 \mathrm{~s}$; then it reached the steady state. The amount of lattice oxygen that was regenerated before $700 \mathrm{~s}$ was $1.7 \times 10^{-5} \mathrm{~mol} \mathrm{g-1}$. 
The total amount of lattice oxygen regenerated during the oxidation reaction with $\mathrm{H}_{2} \mathrm{O}$ was $3.3 \times 10^{-5} \mathrm{~mol} \mathrm{~g}^{-1}$, which was $52 \%$ of the lattice oxygen consumed by ethylbenzene. The reactivity to ethylbenzene was mostly recovered by the oxidation with $\mathrm{H}_{2} \mathrm{O}$. As a result, we found that added $\mathrm{Pd}$ did not change the release rate of lattice oxygen, but enhanced regenerating rate of lattice oxygen in the catalyst. So enhancement of the regenerating rate of lattice oxygen might affect the activity for dehydrogenation of ethylbenzene.

Based on these results, we considered that the mechanism as follows; oxidative dehydrogenation was competitive with and faster than simple dehydrogenation; $\mathrm{H}_{2} \mathrm{O}$ regenerated the surface lattice oxygen, showing high reactivity with ethylbenzene. The surface lattice oxygen was consumed by oxidative dehydrogenation of ethylbenzene and regenerated by $\mathrm{H}_{2} \mathrm{O}$. Previous reports showed that $\mathrm{H}_{2} \mathrm{O}$ inhibited over-reduction of the catalyst. $\mathrm{H}_{2} \mathrm{O}$ also acted as a diluent for shifting the equilibrium conversion higher and inhibited carbon deposition on the catalyst surface. However, in this work we considered that $\mathrm{H}_{2} \mathrm{O}$ had the role of oxidant for the catalyst.

Comparing the result of periodic pulse experiment between the Fe-K catalyst (Fig. 5) and $\mathrm{Pd} / \mathrm{Fe}-\mathrm{K}$ catalyst (Fig. 6), there were no appreciable differences on the conversion of ethylbenzene and the fraction of $\mathrm{H}_{2} \mathrm{O}$. The rate of consumption of the lattice oxygen on each catalyst showed the same value, which was $1.7 \times 10^{-7} \mathrm{~mol} \mathrm{~g}^{-1} \mathrm{~s}^{-1}$. The amount of the lattice oxygen showing high reactivity was $1.7 \times 10^{-5} \mathrm{~mol} \mathrm{~g}^{-1}$, which was $25 \%$ of the amount of surface lattice oxygen. Consequently, we conclude that added Pd changed neither the rate of dehydrogenation of ethylbenzene nor the amount of the lattice oxygen giving high reactivity. On the other hand, the initial conversion of $\mathrm{H}_{2} \mathrm{O}$ to $\mathrm{H}_{2}$ was increased from $20 \%$ to $30 \%$ by adding $\mathrm{Pd}$ to $\mathrm{Fe}-\mathrm{K}$ catalyst at $600 \mathrm{~s}$ in figs. 5 and 6 when $\mathrm{H}_{2} \mathrm{O}$ supplied to the catalyst. We found that surface lattice oxygen was regenerated promptly within $70 \mathrm{~s}$. The initial rate of regeneration of lattice oxygen was increased by adding Pd. At $670 \mathrm{~s}$ of the periodic pulse experiment, regeneration rate of lattice oxygen reached a steady state. $\mathrm{H}_{2} \mathrm{O}$ regenerated $83 \%$ of lattice oxygen consumed by ethylbenzene after steam feed of $600 \mathrm{~s}$, the amount of which was $5.6 \times 10^{-5} \mathrm{~mol} \mathrm{~g}-1$. These results indicated that added $\mathrm{Pd}$ promoted the regeneration of lattice oxygen by $\mathrm{H}_{2} \mathrm{O}$ although it did not affect the rate of dehydrogenation of ethylbenzene or the amount of the lattice oxygen giving a high reactivity. The amount of added Pd was $2.8 \times 10^{-7} \mathrm{~mol} \mathrm{~g}^{-1}$, which was $1.6 \%$ of the surface lattice oxygen giving a high reactivity. We found that the addition of $\mathrm{Pd}$ fewer than the surface lattice oxygen to Fe-K enhanced the catalytic activity.

\subsection{The relation between the regeneration rate and steady-state activity}

We showed that adding Pd improved the dehydrogenation activity by enhancement of regeneration rate of lattice oxygen. In this section, further experiments by changing the amount of $\mathrm{Pd}$ on the Fe-K catalyst were carried out for elucidating redox-type mechanism proceeding on a series of catalyst. The relationship among Pd content on the Fe-K catalyst, styrene formation rate in steady-state and releasing rate of lattice oxygen was investigated. Figure 8 shows the relationship between Pd content on the Fe-K catalyst and the rate of styrene formation/consumption of lattice oxygen. As a result, there was no relation among $\mathrm{Pd}$ concentration on the Fe-K catalyst, the rate of styrene formation and releasing rate of lattice oxygen. Further experiments indicated that added Pd did not affect the property of releasing lattice oxygen. 
Next, the relation between the regeneration rate of lattice oxygen measured by the periodic pulse experiments and the steady-state dehydrogenation activity was examined. The result shows in figure 9. The regeneration rate of lattice oxygen was calculated by the periodic pulse experiments. The steady-state dehydrogenation activity was the conversion of ethylbenzene observed in the continuous reactor.

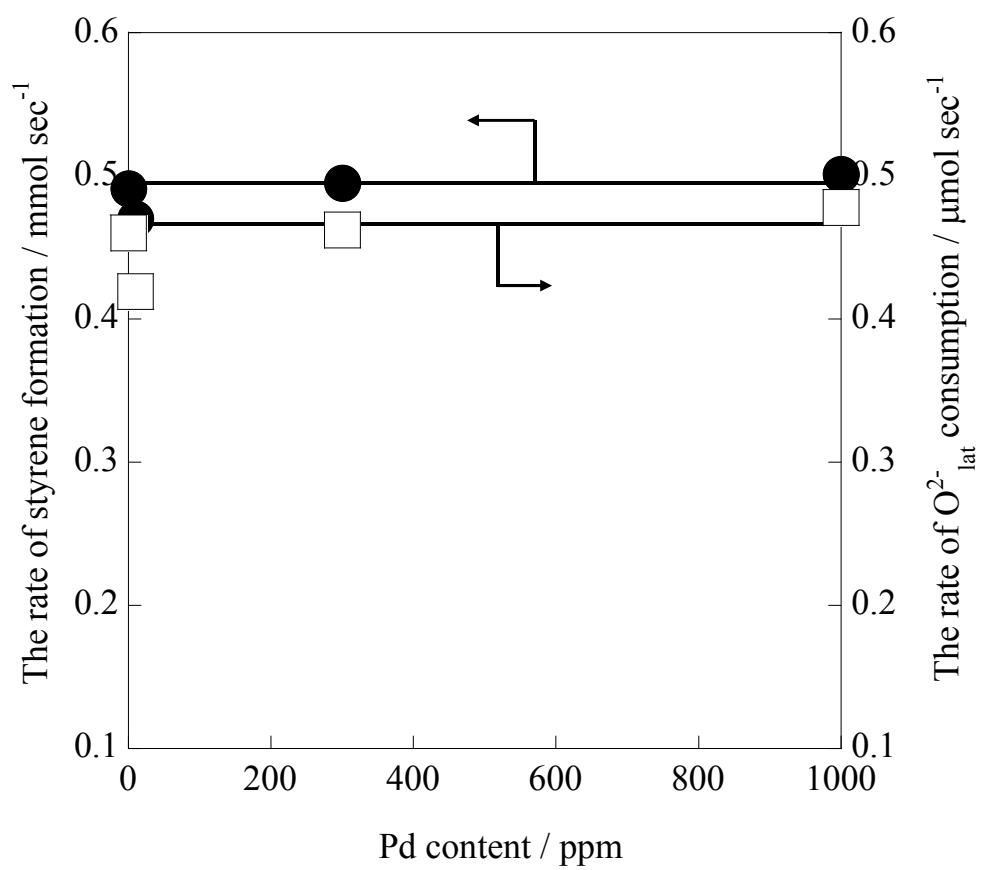

Fig. 8. The effect of $\mathrm{Pd}$ concentration on the styrene formation rate and $\mathrm{O}^{2-}$ lat consumption rate (Sekine et al., 2008).

From figure 9, there was a linear relation between the regeneration rate of lattice oxygen and the steady-state dehydrogenation activity. Hence, the addition of $\mathrm{Pd}$ increased the regeneration rate of lattice oxygen on/in the $\mathrm{Fe}-\mathrm{K}$ catalyst and steady-state activity for dehydrogenation of ethylbenzene. Therefore the promotion of regeneration of lattice oxygen with $\mathrm{H}_{2} \mathrm{O}$ by the addition of small amount of Pd enhanced steady-state activity of the catalyst.

Through these investigations, we developed the precious metal-promoted catalyst based on Fe-K which showed high activity for dehydrogenation of ethylbenzene. And also we found that redox-type mechanism which ethylbenzene was oxidized by mobile surface lattice oxygen and consumed lattice oxygen was regenerated by $\mathrm{H}_{2} \mathrm{O}$ proceeded on a series of catalysts. The effect of an addition of ppm-order-Pd changed neither the rate of oxidative dehydrogenation of ethylbenzene using lattice oxygen nor the amount of the lattice oxygen giving high reactivity. The regeneration rate of lattice oxygen was promoted by Pd addtion, and this result improved the dehydrogenation activity. We elucidated the effectiveness of utilization of steam as an oxidant of the catalyst and the control of activity by control of mobility of lattice oxygen in the catalyst. 


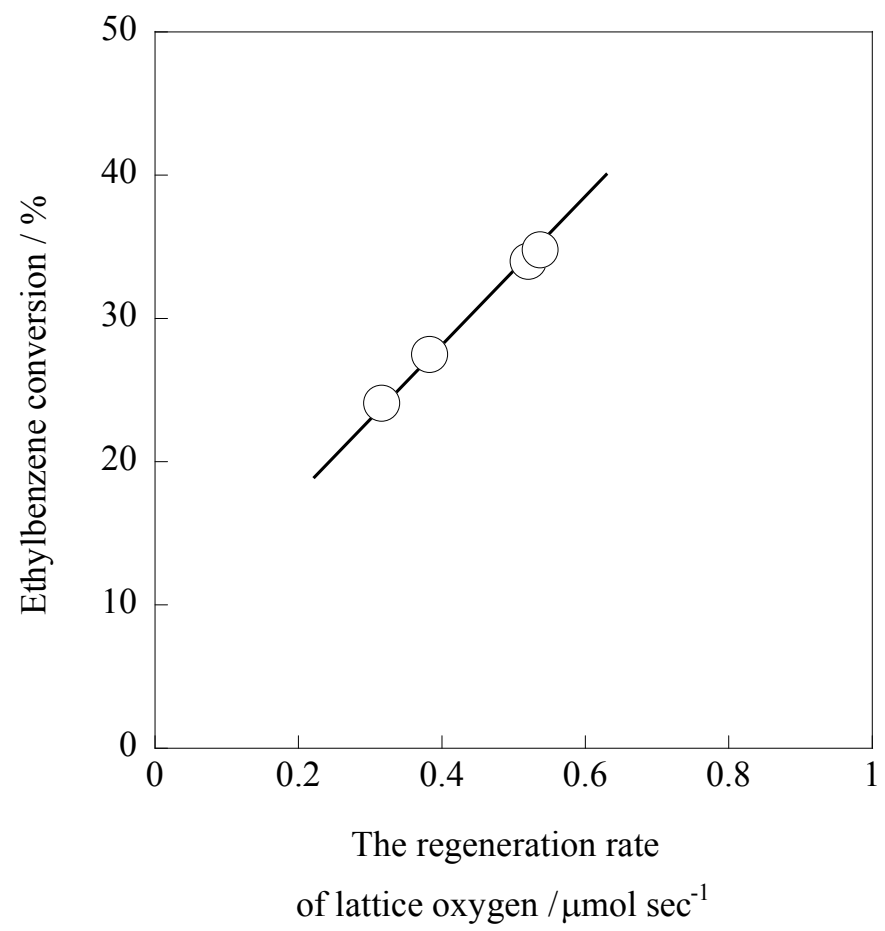

Fig. 9. The relation between regeneration rate of lattice oxygen and ethylbenzene conversion at steady-state (Sekine et al., 2008).

\section{Conclusion}

In this work, we examined the effect of ppm-order Pd addition on the activity of Fe-K mixed oxide catalyst for dehydrogenation of ethylbenzene. Results of periodical pulse experiments indicated that the oxidative dehydrogenation is competitive with and faster than simple dehydrogenation on the $\mathrm{Fe}-\mathrm{K}$ mixed oxide. Consumed lattice oxygen was found to be regenerated by $\mathrm{H}_{2} \mathrm{O}$ immediately. The amount of lattice oxygen showing a high reactivity for dehydrogenation of ethylbenzene was $0.14 \%$ of the total amounts of lattice oxygen in the catalyst, which meant reactive lattice oxygen was surface or subsurface lattice oxygen. We concluded that added Pd hardly changed the rate of dehydrogenation of ethylbenzene or the amount of surface lattice oxygen showing high activity. The surface lattice oxygen, which was regenerated by $\mathrm{H}_{2} \mathrm{O}$ and $\mathrm{Pd}$ promoted the regeneration rate of surface lattice oxygen by $\mathrm{H}_{2} \mathrm{O}$.

\section{References}

Addiego, W.P., Estrade, C.A., Goodman, D.W. \& Rosynek. P. (1994). An infrared study of the dehydrogenation of ethylbenzene to styrene over iron-based catalysts, Journal of Catalysis, 146: 407-414. 
Addiego, W.P., Liu, W. \& Boger. T. (2001). Iron oxide-based honeycomb catalysts for the dehydrogenation of ethylbenzene to styrene, Catalysis Today, 69: 25-31.

Busca, G., Zerlia, T., Lorenzelli, V. \& Girelli, A. (1984). Fourier transform-infrared study of the adsorption of unsaturated and aromatic hydrocarbons on the surface of a$\mathrm{Fe}_{2} \mathrm{O}_{3}$ : I. Ethylene, Journal of Catalysis, 88: 125-130.

Carrà, S. \& Forni, L. (1965). Kinetics of Catalytic Dehydrogenation of Ethylbenzene to Styrene, Industrial E Engineering Chemistry Research, 4(3): 281-285.

Coulter, K. \& Goodman D.W. (1995). Kinetics of the dehydrogenation of ethylbenzene to styrene over unpromoted and K-promoted model iron oxide catalysts, Catalysis Letters, 31: 1-8.

Devoldere, K.R. \& Froment, G.F. (1999). Coke formation and gasification in the catalytic dehydrogenation of ethylbenzene, Industrial \& Engineering Chemistry Research, 38(7): 2626-2633.

Eggertsen, F.T. \& Voge, H.H. (1947). Catalytic dehydrogenation, U.S. Patent No. 2,414,585.

Herzog, B.D. \& Rase, H.F. (1984). In situ catalyst reactivation: used ethylbenzene dehydrogenation catalyst with agglomerated potassium promoter, Industrial $\mathcal{E}$ Engineering Chemistry Product Research and Development, 23(2): 187-196.

Hirano, T. (1986). Roles of potassium in potassium-promoted iron oxide catalyst for dehydrogenation of ethylbenzene, Applied Catalysis, 26: 65-79.

Hirano, T. (1986). Active phase in potassium-promoted iron oxide catalyst for dehydrogenation of ethylbenzene, Applied Catalysis, 26: 81-90.

Lee, E.H. (1974). Iron oxide catalysts for dehydrogenation of ethylbenzene in the presence of steam, Catalysis Reviews, 8(1): 285-305.

Kearby, K.K. \& Elizabeth, N. J. (1945). Method for the catalytic dehydrogenation of hydrocarbon, U.S. Patent No. 2,370,797.

Meima, P.G. \& Menon, P.G. (2001). Catalyst deactivation phenomena in styrene production, Applied Catalysis A: General, 212: 239-245.

Miura, H., Ansai, R. \& Kawai, H. (1994). Deuterium exchange reaction of ethylbenzene over an $\mathrm{Fe}_{2} \mathrm{O}_{3}-\mathrm{K}_{2} \mathrm{CO}_{3}-\mathrm{Cr}_{2} \mathrm{O}_{3}$ catalyst, Reaction Kinetics and Catalysis Letters, 53(2): 323-329.

Muhler, M., Schlögl, R., Reller, A. \& Ertl, G. (1989). The nature of the active phase of the FeK-catalyst for dehydrogenation of ethylbenzene, Catalysis Letters, 2: 201-210.

Muhler, M., Schlögl, R. \& Ertl, G. (1992). The nature of the iron oxide-based catalyst for dehydrogenation of ethylbenzene to styrene 2. Surface chemistry of the active phase, Journal of Catalysis, 138: 413-444.

O'Hara F.J. (1975). Dehydrogenation catalyst, U.S. Patent No. 3,904,552.

Pitzer, E.W. (1957). Catalyst and dehydrogenation process, U.S. Patent No. 2,866,790.

Riesser, G.H. (1979). Dehydrogenation catalyst, US Patent 4,144,197.

Sekine, Y., Watanabe, R., Matsukata, M. \& Kikuchi, E. (2008). High Performance of Fe-K Oxide Catalysts for Dehydrogenation of Ethylbenzene to Styrene with an aid of ppm-order Pd, Catalysis Letters, 125: 215-219.

Shekhah, O., Ranke, W. \& Schlögl. R. (2004). Styrene synthesis: in situ characterization and reactivity studies of unpromoted and potassium-promoted iron oxide model catalysts, Journal of Catalysis, 225: 56-68. 
Urasaki, K., Tanimoto N., Hayashi, T., Sekine, Y., Kikuchi, E. \& Matsukata, M. (2005). Hydrogen production via steam-iron reaction using iron oxide modified with very small amounts of palladium and zirconia, Applied Catalysis A: General, 288: 143-148.

Weiss, W. \& Schlögl, R. (2000). An integrated surface science approach towards metal oxide catalysis, Topics in Catalysis, 13: 75-90.

Williams, D., Mishima, Y., Andrei, R., Niiyama, K. \& Danish, S. (2002). Jpn Patent No. 2002509,790.

Zhu, X.M., Schön, M. Bartmann, U., Veen, A.C. \& Muhler, M. (2004). The dehydrogenation of ethylbenzene to styrene over a potassium-promoted iron oxide-based catalyst: a transient kinetic study, Applied Catalysis A: General, 266: 99-108. 


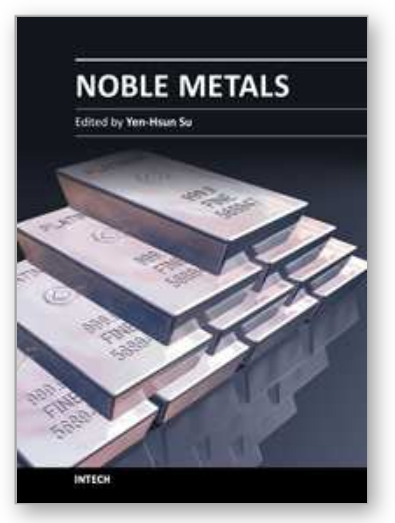

\author{
Noble Metals \\ Edited by Dr. Yen-Hsun Su
}

ISBN 978-953-307-898-4

Hard cover, 426 pages

Publisher InTech

Published online 01, February, 2012

Published in print edition February, 2012

This book provides a broad spectrum of insights into the optical principle, resource, fabrication, nanoscience, and nanotechnology of noble metal. It also looks at the advanced implementation of noble metal in the field of nanoscale materials, catalysts and biosystem. This book is ideal not only for scientific researchers but also as a reference for professionals in material science, engineering, nonascience and plasmonics.

\title{
How to reference
}

In order to correctly reference this scholarly work, feel free to copy and paste the following:

Ryo Watanabe, Yasushi Sekine, Masahiko Matsukata and Eiichi Kikuchi (2012). The Effect of Addition of ppmOrder-Pd to Fe-K Catalyst on Dehydrogenation of Ethylbenzene, Noble Metals, Dr. Yen-Hsun Su (Ed.), ISBN: 978-953-307-898-4, InTech, Available from: http://www.intechopen.com/books/noble-metals/the-effect-ofaddition-of-ppm-order-pd-to-fe-k-catalyst-on-dehydrogenation-of-ethylbenzene

\section{INTECH}

open science | open minds

\author{
InTech Europe \\ University Campus STeP Ri \\ Slavka Krautzeka 83/A \\ 51000 Rijeka, Croatia \\ Phone: +385 (51) 770447 \\ Fax: +385 (51) 686166 \\ www.intechopen.com
}

\author{
InTech China \\ Unit 405, Office Block, Hotel Equatorial Shanghai \\ No.65, Yan An Road (West), Shanghai, 200040, China \\ 中国上海市延安西路65号上海国际贵都大饭店办公楼 405 单元 \\ Phone: +86-21-62489820 \\ Fax: $+86-21-62489821$
}


(C) 2012 The Author(s). Licensee IntechOpen. This is an open access article distributed under the terms of the Creative Commons Attribution 3.0 License, which permits unrestricted use, distribution, and reproduction in any medium, provided the original work is properly cited. 